\title{
Development and operating experience of a short-period superconducting undulator at the Advanced Photon Source
}

\author{
Y. Ivanyushenkov, ${ }^{*}$ K. Harkay, M. Abliz, L. Boon, M. Borland, D. Capatina, J. Collins, \\ G. Decker, R. Dejus, J. Dooling, C. Doose, L. Emery, J. Fuerst, J. Gagliano, Q. Hasse, M. Jaski, \\ M. Kasa, S. H. Kim, R. Kustom, J. C. Lang, J. Liu, E. Moog, D. Robinson, V. Sajaev, \\ K. Schroeder, N. Sereno, Y. Shiroyanagi, D. Skiadopoulos, M. Smith, X. Sun, E. Trakhtenberg, \\ I. Vasserman, A. Vella, A. Xiao, J. Xu, A. Zholents, and E. Gluskin \\ APS, Argonne National Laboratory, 9700 South Cass Avenue, Argonne, Illinois 60439, USA \\ V. Lev, N. Mezentsev, V. Syrovatin, and V. Tsukanov \\ Budker Institute of Nuclear Physics, Novosibirsk 630090, Russia
}

A. Makarov

FNAL, Batavia, Illinois 60510, USA

J. Pfotenhauer and D. Potratz

University of Wisconsin, 1500 Engineering Drive, Madison, Wisconsin 53706, USA (Received 17 December 2014; published 29 April 2015)

\begin{abstract}
A decade-long effort at the Advanced Photon Source (APS) of Argonne National Laboratory (ANL) on development of superconducting undulators culminated in December 2012 with the installation of the first superconducting undulator "SCU0" into Sector 6 of the APS storage ring. The device was commissioned in January 2013 and has been in user operation since. This paper presents the magnetic and cryogenic design of the SCU0 together with the results of stand-alone cold tests. The initial commissioning and characterization of SCU0 as well as its operating experience in the APS storage ring are described.
\end{abstract}

DOI: 10.1103/PhysRevSTAB.18.040703

PACS numbers: 07.85.Qe, 84.71.Ba

\section{INTRODUCTION}

Superconducting magnets and superconducting wigglers have been successfully employed at various low and medium energy synchrotron light sources for generation of high energy photons using high magnetic fields not attainable with conventional magnets [1-7]. Undulators are much brighter radiation sources, but require small periods and near-ideal magnetic fields. In contrast with wigglers, magnetic field errors of undulators need to be kept very small to achieve high flux of radiation harmonics. While correcting field errors is relatively simple in permanent magnet or hybrid undulator devices, it is much more difficult in superconducting devices, thus, a precise fabrication of a superconducting magnet is required. Another difficult aspect in building a superconducting undulator (SCU) is construction of a low heat loss cryogenic system capable of maintaining a sufficiently low temperature in the undulator magnet using a small number of cryocoolers. A part of this challenge is an integration of the device into a storage ring

\footnotetext{
*yury@aps.anl.gov

Published by the American Physical Society under the terms of the Creative Commons Attribution 3.0 License. Further distribution of this work must maintain attribution to the author $(s)$ and the published article's title, journal citation, and DOI.
}

lattice avoiding an excessive heat load induced by the electron beam and synchrotron radiation from the upstream magnetic devices. Yet another challenge is precise measurement of the magnetic field in a device embedded into a cryostat that severely limits access to the device.

The slow pace of deployment of SCUs is, perhaps, a direct manifestation of these and other difficulties. So far there are only two SCUs in operation worldwide; one is installed at the ANKA light source [8] and the other, described in this paper, is installed at the Advanced Photon Source (APS). The main motivation for the development of the SCU for the APS is the potential improvement of the x-ray brightness illustrated in Fig. 1. Here we compare the brightness of two superconducting undulators (SCUs) and two hybrid permanent magnet undulators (HPMUs). For both the SCUs and HPMUs, the same minimum magnetic gap of $9.5 \mathrm{~mm}$ and vacuum gap of $7 \mathrm{~mm}$ are assumed for direct comparison. A 3.3-cm-period HPMU, popular at the APS, is chosen because it is used in the comparison of the measured photon flux of the SCU0, as described later in the paper. A 2.9-cm-period HPMU is also shown to illustrate that higher brightness could be obtained with this type of undulator having a smaller period length. The energy coverage is still continuous but it has a higher cutoff at the low-energy end compared to the $3.3-\mathrm{cm}$ HPMU. For the SCUs, the SCU0 described in this paper, 


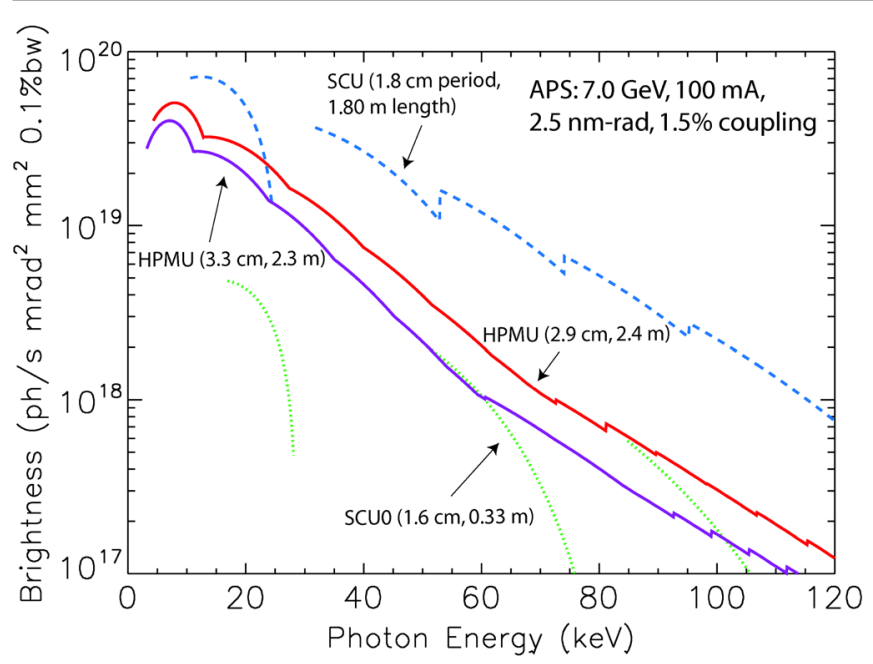

FIG. 1. The X-ray brightness as a function of photon energy for two hybrid permanent magnet undulators and two superconducting undulators. The period length and the magnetic length of each device are given in the figure.

is shown. A 1.8-cm-period SCU is chosen as well to show the performance of a device with a nearly continuous energy coverage above $30 \mathrm{keV}$. The magnetic length for this undulator is chosen such that it fits inside a $2.4-\mathrm{m}$ long cryostat that occupies the same space as a 2.4-m long HPMU. Clearly the SCUs outperform the HPMUs in terms of brightness by a large margin approaching an order of magnitude at high photon energies.

The undulator SCU0 described in this paper, is the first superconducting undulator built at the APS. It was commissioned with the electron beam at APS in January of 2013 and has remained in operation since then. The "transition to operation" culminated a long process of development of superconducting undulator technology at APS, which is described elsewhere [9].

In this paper we first give a concise description of the SCU0, with an emphasis on magnetic design, expected heat loads, and cooling system design. We then describe the results of a stand-alone cool-down test, including magnetic measurements and cryogenic behavior of the SCU0. Finally, we review our experience of operating the SCU0 in the APS storage ring, presenting the observed heat loads in the SCU0, the undulator performance, and its effect on the electron beam.

\section{DESIGN OF SCUO}

The goal of building SCU0 was to validate the design concept and to gain experience in operating a superconducting undulator at the APS. The undulator design parameters, given in Table I, were chosen to deliver 20-25 keV photon energy at the fundamental.

Below we present the main conceptual points of the SCU0 design. A more detailed description can be found in [10-12].
TABLE I. Design parameters of SCU0.

\begin{tabular}{lc}
\hline \hline Parameter & Value \\
\hline Electron beam energy $(\mathrm{GeV})$ & 7 \\
Photon energy at the fundamental (keV) & $20-25$ \\
Period length (mm) & 16 \\
Number of periods & 20.5 \\
Vacuum gap (mm) & 7.2 \\
Magnetic gap (mm) & 9.5 \\
Design magnetic field (T) & 0.64 \\
Design operating current (A) & 500 \\
Design undulator parameter K & 0.96 \\
Magnetic length (m) & 0.33 \\
Cryostat length (m) & 2.063 \\
\hline \hline
\end{tabular}

${ }^{\mathrm{a}}$ Cryostat can accommodate a 1.2-m long undulator magnet.

\section{A. Magnetic design}

As in planar permanent magnet or hybrid undulators, the magnetic field in the superconducting planar undulator is created by a pair of identical magnets, separated by a vertical gap which accommodates a beam vacuum chamber. Each magnet is a series of vertical racetrack superconducting coil packs wound onto a former, or a core [13]. The adjacent coil packs with currents flowing in opposite directions are separated by magnetic poles.

An assembled design of the magnetic core [10] was chosen where individual, precisely ground and lapped poles are inserted in slots machined in the ground and polished sub-core, as shown in Fig. 2. A superconducting wire is then wound in the rectangular groves between the poles. In such a design, the groove surfaces have $0.4-\mu \mathrm{m}$ finish to help avoid electrically shorting the wire to the core in the winding process. The design model of the SCU0 core is shown in Fig. 3.

The SCU0 magnets are wound with a round $\mathrm{NbTi}$ 0.7-mm wire available from Supercon Inc. [14]. Parameters of the wire are presented in Table II. Each magnet has a main coil with 39 turns per winding pack (fewer in the last two grooves at each end of the core), and two correction coils that are wound on top of the main coil in the last two end grooves. The correction coils are separately powered and are used for tuning the first- and second-integrals of the vertical magnetic field [15].

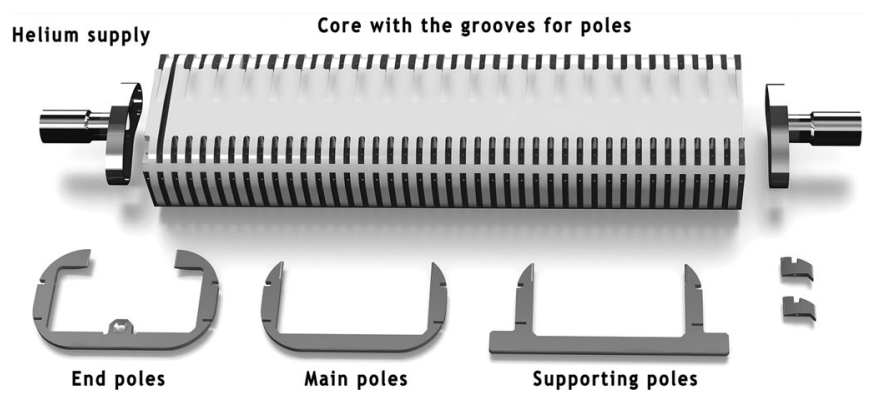

FIG. 2. Main parts of the SCU0 magnetic core. 


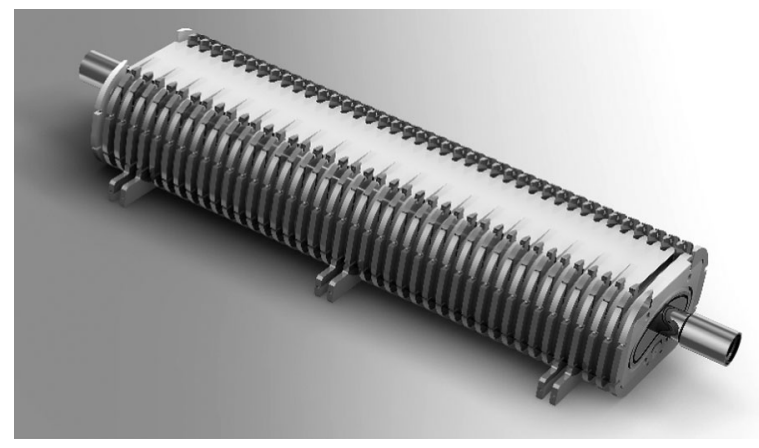

FIG. 3. Design model of the SCU0 core.

The technological steps of the magnet manufacture included winding the superconducting wire onto the cores using a computer controlled winding machine. A winding scheme was developed in the $R \& D$ phase of the project and described in [16]. The SCU0 core is designed to wind the undulator coil first in one direction into every other groove for the full length. After making a 180-degree turn, the superconducting wire is then similarly wound into the alternate grooves in the opposite direction forming an undulator magnet coil without any splicing. The magnet cores were then impregnated with epoxy resin in a special mold. The completed magnets were tested separately or in an assembly in a vertical liquid helium (LHe) bath cryostat. The test included initial magnet "training" and a preliminary measurement of the undulator field with a Hall probe.

The SCU0 magnetic assembly consisting of two magnets is shown in Fig. 4.

\section{B. Cryostat and cooling system}

The design of SCU0 cryostat is based on the concept developed at the Budker Institute of Nuclear Physics (INP), Novosibirsk, Russia, and implemented in the superconducting wigglers that have been built by the INP team for a number of light sources worldwide [17]. The 2-m long cryostat is designed to accommodate a 1.2-m long magnet, but in the case of the SCU0, it holds a relatively short magnetic structure, as shown in Fig. 5. The second superconducting undulator for the APS, SCU1, uses the same cryostat design to hold a longer magnet.

The SCU0 cryostat is a stainless-steel vacuum vessel that contains two copper radiation shields and a cold mass. The cold mass consists of the superconducting magnet assembly including a beam vacuum chamber, and a 100-liter liquid

TABLE II. Parameters of Supercon 56S53 NbTi wire [14].

\begin{tabular}{lc}
\hline \hline Parameter & Value \\
\hline Bare diameter $(\mathrm{mm})$ & 0.7 \\
Insulated diameter $(\mathrm{mm})$ & 0.753 \\
Cu:Sc ratio & $0.9: 1$ \\
Number of filaments & 56 \\
Filament diameter $(\mu \mathrm{m})$ & 68 \\
\hline \hline
\end{tabular}

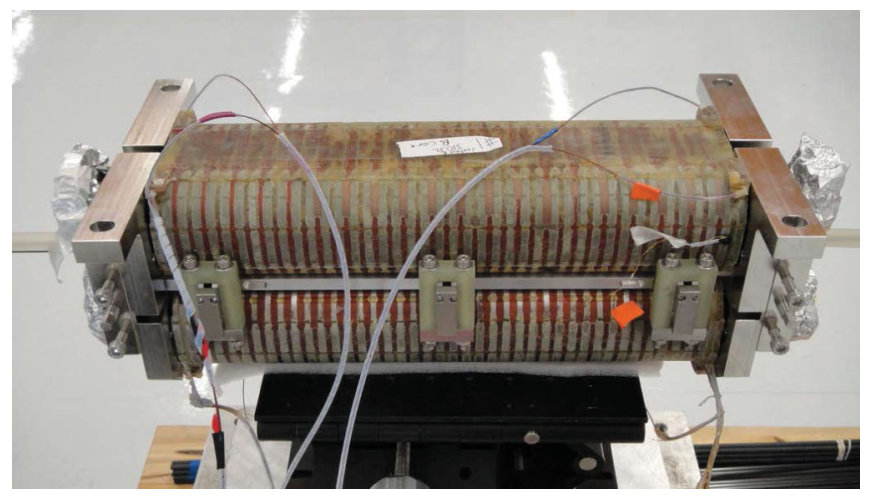

FIG. 4. Photograph of SCU0 magnetic assembly.

helium tank with piping making a closed loop 4-K circuit. The central part of the beam vacuum chamber is made of aluminum alloy 6063-T5 with two stainless-steel transitions on both ends. A stainless-steel frame supports both the magnet assembly and the LHe tank and is supported inside the vacuum vessel by a set of Kevlar strings. The cryostat also incorporates two turrets not visible in Fig. 5, and a helium fill turret.

It is important to note that the beam-induced heating is actually applied to the vacuum chamber through which the electron beam passes. If the superconducting magnet coils were to be in direct thermal contact with the vacuum chamber, this heat would be transferred to the superconducting magnet, which is undesirable. One of the most important conceptual points in the SCU0 design is that the SCU0 coils are thermally isolated from the vacuum chamber. This substantially reduces the heat load from the beam on the superconducting magnet. The vacuum chamber can then be cooled independently and does not need to be at the temperature-typically $4 \mathrm{~K}$ - of the superconducting coils. This solution opens a way of cooling the vacuum chamber with cryocoolers, the cooling capacity of which rises with temperature.

The superconducting coils are cooled indirectly by LHe that passes through channels in the magnet cores. The flow of liquid helium through these channels is driven by the thermosiphon effect [18]. Since, as far as we know, the thermosiphon concept has not been used before in superconducting wigglers or undulators, an R\&D program dedicated to verifying the concept was carried out at the APS in collaboration with the University of Wisconsin Madison. Measurements were conducted in a speciallyconstructed cryostat using a test pipe structure with hydraulic properties similar to those of a single magnet core. Test results indicated that helium circulation via the predominantly horizontal thermosiphon could be enhanced with an additional heater mounted on a vertical helium return pipe [12]. Provision for such a heater has been implemented in the SCU cryostat design [11].

The SCU0 cooling system consists of four 2-stage cryocoolers delivering cooling power at three temperature 


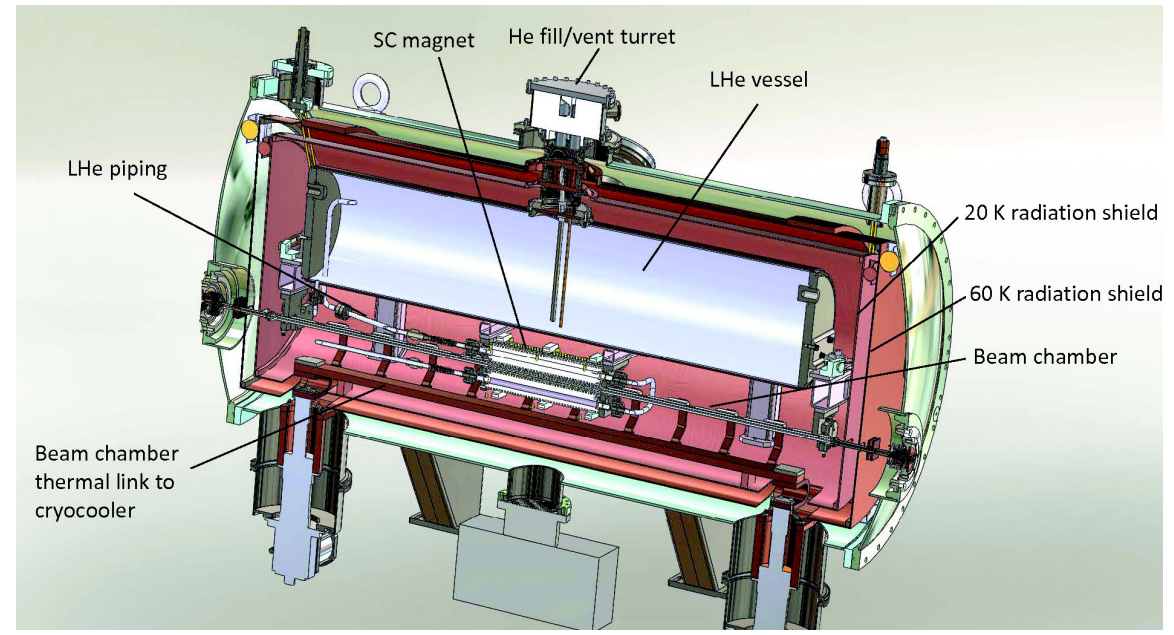

FIG. 5. Solid model cutaway view of the inside of the SCU0 cryostat.

levels of roughly $4 \mathrm{~K}, 20 \mathrm{~K}$, and $60 \mathrm{~K}$ (the design values). The first stage of all four units cools the outer thermal shield to a temperature below $60 \mathrm{~K}$ as shown on a cooling scheme conceptual diagram in Fig. 6. The upper ends of all the high-temperature superconductor (HTS) current leads (two 1-kA-rated leads for the main magnet coils plus four 100-A-rated leads for corrector coils) also receive cooling at this temperature level, primarily from the upper two cryocoolers. The cryocooler second stages operate at different temperatures depending on their connected thermal loads. The upper two cryocoolers (with a design cooling power of $1.5 \mathrm{~W}$ total at $4 \mathrm{~K}$ ) are connected to the liquid helium reservoir and recondense helium vapor back to liquid. The superconducting magnet cores are connected with piping to the LHe reservoir, thus making a closed helium circuit. The lower two cryocoolers (with a design cooling power of $20 \mathrm{~W}$ each at $20 \mathrm{~K}$ ) are connected to the vacuum chamber via a copper thermal bus and

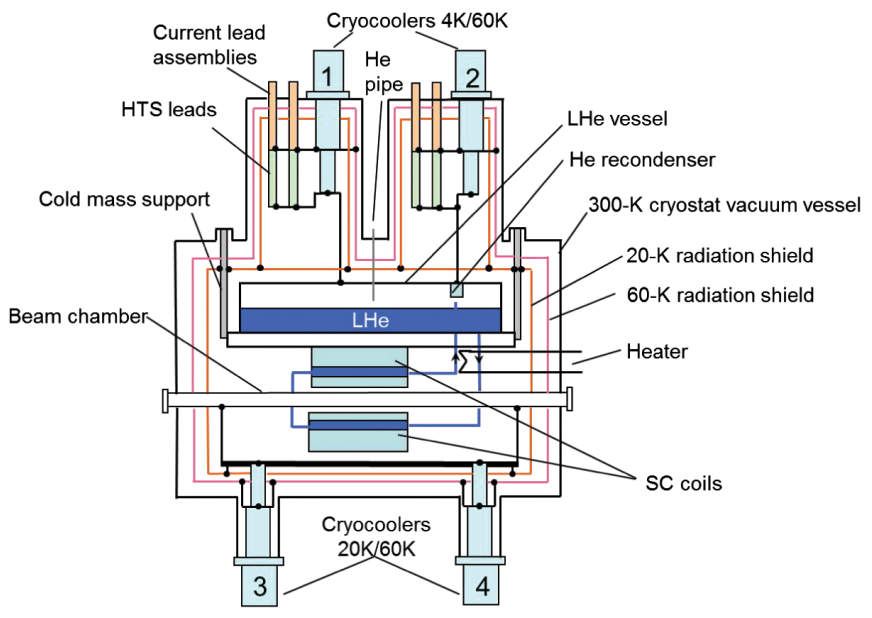

FIG. 6. SCU0 cooling scheme concept. thermal links. Those two cryocoolers also cool the internal radiation shield.

\section{Design heat loads}

As noted earlier, the analysis of anticipated heat loads on the superconducting magnet is crucial for the design of the superconducting undulator cooling circuit. The total heat load in the superconducting undulator includes both static heat loads, which are typical for superconducting magnets, and the heat load from the electron beam. The latter includes heating of the SCU vacuum chamber by beaminduced image currents, synchrotron radiation generated in upstream dipole magnets, wakefield effects, particle losses, and electron cloud-induced multipacting [19-21]. Under nominal operating conditions $\mathrm{CW}$ (or equilibrium) heat loads are present from several of these effects, while specific machine fault conditions may occur that give rise to particular transient heat loads.

Predictions of the various contributions to the $\mathrm{CW}$ heat load due to the stored beam of $100 \mathrm{~mA}$ are described below and summarized in Table III, assuming operation with 24 uniformly spaced bunches and $10-\mathrm{mm} \mathrm{rms}$ bunch length. The central part of the SCU0 vacuum chamber is nominally at $20 \mathrm{~K}$ and is thermally isolated from the 4-K

TABLE III. Predicted beam-related heat loads on 2-m-long SCU0 vacuum chamber, assuming $100 \mathrm{~mA}$ beam current.

\begin{tabular}{lc}
\hline \hline Heat source & Heat loads at $20 \mathrm{~K}(60 \mathrm{~K})$ \\
\hline CW heat loads & \\
Image current (W) & $4.7(6)$ \\
Wakefields (W) & $<0.5$ \\
Injection losses (W) & 2 \\
Synchrotron radiation (W) & 0.2 \\
Average particle losses (W) & $\sim 0.1$ \\
Electron cloud (W) [21] & $<2$ \\
Total CW heat load $(W)$ & $<9.5(6)$ \\
\hline \hline
\end{tabular}


superconducting magnet. The chamber cold-to-warm transitions are in the 60- to $300-\mathrm{K}$ region. Where appropriate, the heat loads at $20 \mathrm{~K}$ and $60 \mathrm{~K}$ are given separately.

For calculation of resistive wall heating, temperaturedependent resistivity values [22,23] and numericallymodeled values of the current-dependent bunch length [24] were used. The Bane/Krinsky impedance model was used [25], and anomalous skin effects were included in the case of Al at $10 \mathrm{~K}$ [26]. Surface roughness increases the surface resistance and, thereby, the power deposited on the walls. Therefore the SCU0 chamber was polished to obtain surface roughness on the order of $0.1 \mu \mathrm{m} \mathrm{rms}$, which limits the roughness-related increase in power to only $10 \%$.

Another important source of SCU vacuum chamber heating is the flux of photons from an upstream dipole magnet. Large orbit displacement and/or angle errors in the dipole can potentially cause a synchrotron radiation heat load of $>25 \mathrm{~W}$ on the SCU0 chamber walls. Mitigation of this potentially substantial heating is achieved by using a photon absorber to mask the SCU0 chamber walls, and by restricting the electron beam steering in the dipole radiation source. The resulting heat load is then reduced to the level of $<1 \mathrm{~W}$.

Care was taken to design the chamber transitions to minimize the wakefield heating in the warm-to-cold transition tapers. The wakefields were computed in the frequency and time domains using CST Microwave Studio. Based on this, the heat load was computed using 36 electromagnetic field modes, giving $<2 \mathrm{~W}$ on the tapers.

Based on these analyses, the maximum CW heat load on the vacuum chamber during normal operation was estimated to be less than $9.5 \mathrm{~W}$. The design value for the heat load at the $20-\mathrm{K}$ stage was increased to $12 \mathrm{~W}$ to include a small margin as well as an additional heat load on the inner thermal shield that is also connected to this thermal stage. The SCU0 20-K stage cooling system has a capacity of $40 \mathrm{~W}$, as listed in Table IV, which provides a comfortable margin for normal operation. Transient heat loads could potentially occur under various fault conditions that cause beam orbit displacement or angle errors; peak heating up to $25 \mathrm{~W}$ over a short time interval of $\lesssim 1 \mathrm{sec}$ is possible. Temperature monitoring using thermal sensors mounted on the chamber detects anomalous heating, and temperature interlocks shut off the SCU0 power supply to prevent the magnet from quenching.

TABLE IV. Design heat loads and installed cooling capacity.

\begin{tabular}{lccc}
\hline \hline & \multicolumn{4}{c}{ Design Installed } \\
Heat source & $(\mathrm{K})$ & (W) & (W) \\
\hline Magnet & 4.2 & 0.5 & $\sim 1.5$ \\
$\begin{array}{l}\text { Vacuum chamber and inner } \\
\text { radiation shield }\end{array}$ & 20 & 12 & 40 \\
Outer radiation shield & 60 & 86 & 224 \\
\hline \hline
\end{tabular}

\section{COLD TEST RESULTS}

\section{A. Cryogenic test}

Before installation in the APS storage ring, SCU0 performance was thoroughly tested. The device was cooled down and kept cool for almost two months. The cool-down strategy is to establish insulating vacuum, purify the helium circuit by multiple cycles of evacuation followed by repressurization with pure helium gas, and then start all four cryocoolers. Cool-down is essentially completed after two days, after which the process is finished by transferring about 50 liters of liquid helium into the liquid helium reservoir. This fills the reservoir halfway, leaving about $0.2 \mathrm{~m}^{2}$ surface area within the reservoir to enable efficient helium recondensation. The temperatures of the SCU0 cryocoolers recorded during the cool down are shown in Fig. 7. When required, a warm-up process is accomplished using heaters installed in the cryomodule. A four-day warm-up period is typical.

In the stand-alone test the observed temperatures in the SCU0 were lower than or equal to the design temperatures, indicating lower than expected static heat leaks in the system. The design and measured temperatures are summarized in Table V.

In the interest of brevity, from this point forward we will use the observed temperature levels to describe three SCU0 thermal stages as $4 \mathrm{~K}, 10 \mathrm{~K}$, and $30 \mathrm{~K}$.

Operation of the SCU0 without helium loss was observed over the 1.5 -month test period. It was also observed that cooling power exceeded the static heat loads enabling the possibility of building liquid helium inventory if so desired. This is accomplished by connecting a regulated supply of pure helium gas to the SCU0 helium circuit. The helium condensation rate matches the surplus cooling power. With zero beam heating and zero magnet current, the rate of helium collection is about 0.23 liters/hour. The resulting rise in liquid helium level within the reservoir during the test is shown in Fig. 8.

The effect of electron beam heating was simulated during the stand-alone test by using heaters mounted on

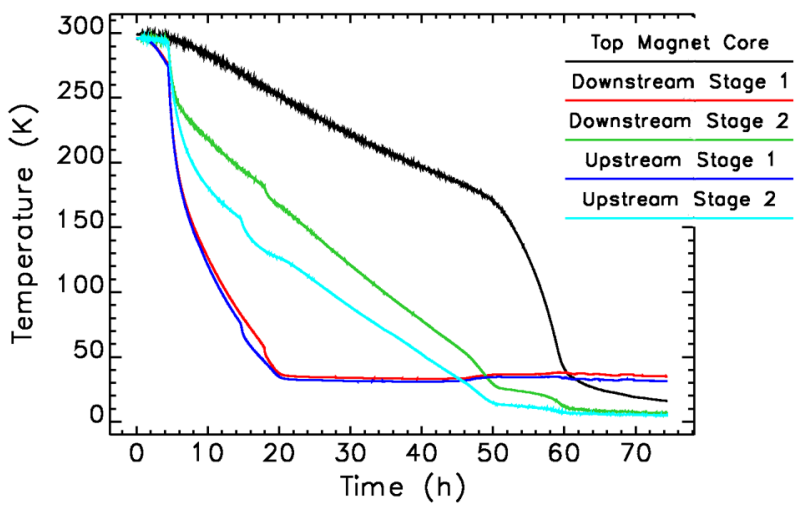

FIG. 7. SCU0 $4 \mathrm{~K}$ cryocooler stage and top magnet core temperatures during the cool down process. 
TABLE V. SCU0 design and observed temperatures in the stand-alone test.

\begin{tabular}{lcc}
\hline \hline & $\begin{array}{c}\text { Design } \\
\text { temperature } \\
(\mathrm{K})\end{array}$ & $\begin{array}{c}\text { Observed } \\
\text { temperature } \\
(\mathrm{K})\end{array}$ \\
\hline LHe circuit & 4.2 & $4.2-4.3$ \\
Vacuum chamber and inner & 20 & $7-8$ \\
$\quad$ radiation shield & & $32-33$ \\
Outer radiation shield & 60 & \\
\hline \hline
\end{tabular}

the cold part of the SCU0 vacuum chamber. As Table VI shows, a vacuum chamber temperature rise of almost $20 \mathrm{~K}$ was observed with $45 \mathrm{~W}$ of heat applied to the chamber, but the temperature of the LHe circuit increased by only about $0.15 \mathrm{~K}$. This demonstrates good thermal isolation between the SCU0 magnet and the vacuum chamber. As expected, the magnet did not quench during this test.

\section{B. Magnetic measurements}

A crucial part of the cold test was SCU0 magnetic performance characterization. For this purpose a dedicated magnetic measurement system was built [27,28]. The system includes a moving Hall probe for field mapping and wire coils for measurements of field integrals.

The SCU0 magnet coils achieved the design excitation current of $500 \mathrm{~A}$ and delivered the design field of $0.64 \mathrm{~T}$ on the first current ramp without quenching. After two more quenches a current of $600 \mathrm{~A}$ was reached, and with three more additional quenches a current of $700 \mathrm{~A}$ was achieved, thus expanding the operating range. It is worth mentioning that at the design current of $500 \mathrm{~A}$ the SCU0 NbTi superconductor operates at about $60 \%$ of the critical current of a short sample, while the operating currents of $600 \mathrm{~A}$ and 700 A correspond to about $72 \%$ and $85 \%$, respectively, of the critical current of a short sample. We were able to operate the magnet at $700 \mathrm{~A}$ when the heater on the LHe

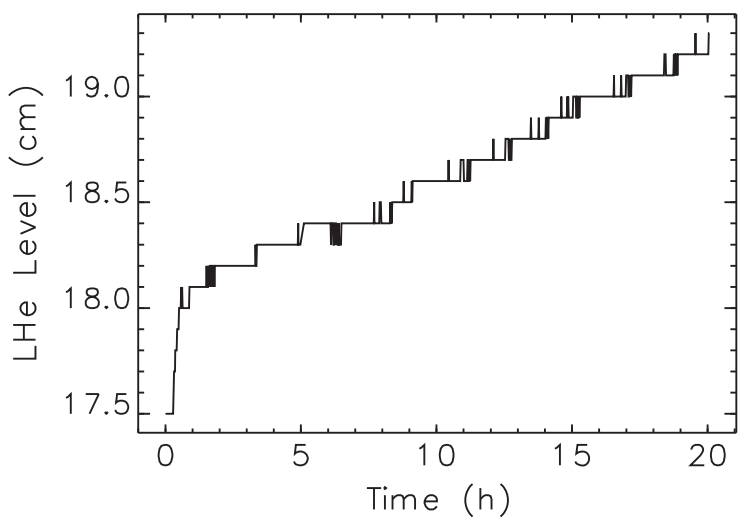

FIG. 8. Helium liquefaction using excess refrigeration capacity. Steps in the data represent the resolution of the helium liquid level probe.
TABLE VI. Observed temperature changes during beam heat load simulation test.

\begin{tabular}{lcccc}
\hline \hline Heater power $(\mathrm{W})$ & 0 & 10 & 20 & 45 \\
\hline Vacuum chamber temperature $(\mathrm{K})$ & 10.6 & 13.5 & 16.3 & 30.0 \\
LHe tank temperature $(\mathrm{K})$ & 4.29 & 4.30 & 4.30 & 4.44 \\
\hline \hline
\end{tabular}

circuit was off, and the LHe temperature dropped to $3.8 \mathrm{~K}$. The simulated and measured SCU0 magnet excitation curves are shown in Fig. 9 together with undulator parameter K. A typical measured field profile is shown in Fig. 10, and a corresponding calculated electron trajectory is shown in Fig. 11. The measured field errors characterized by so-called undulator phase errors [29] were below 2 degrees rms for currents from $100 \mathrm{~A}$ to $600 \mathrm{~A}$, and the measured rms field errors at the peaks (Fig. 10) were less than $0.3 \%$, essentially independent of the magnet current. The higher harmonic content of the measured magnetic field was also analyzed. For the SCU0, it was typically less than $0.2 \%$ for $b_{3} / b_{1}$ and less than $0.1 \%$ for $b_{5} / b_{1}$ where $b_{1}$ is the magnitude of the fundamental, and $b_{3}$ and $b_{5}$ are the amplitudes of the 3rd and the

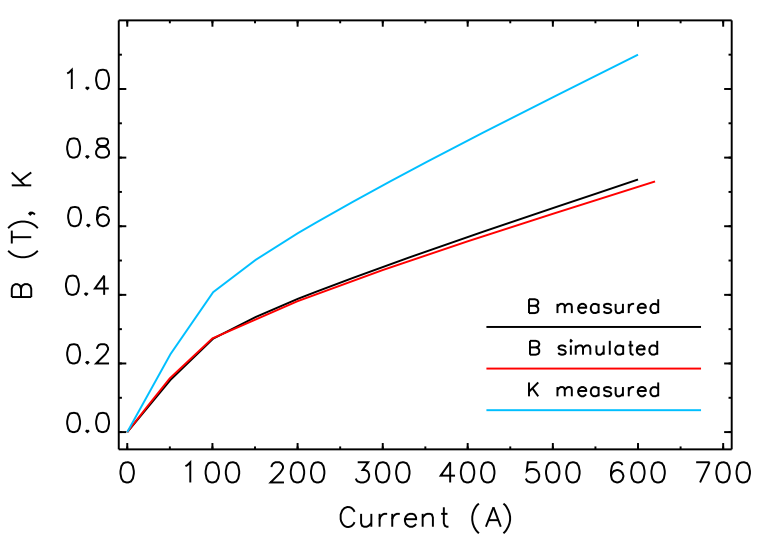

FIG. 9. Measured SCU0 magnet excitation curve.

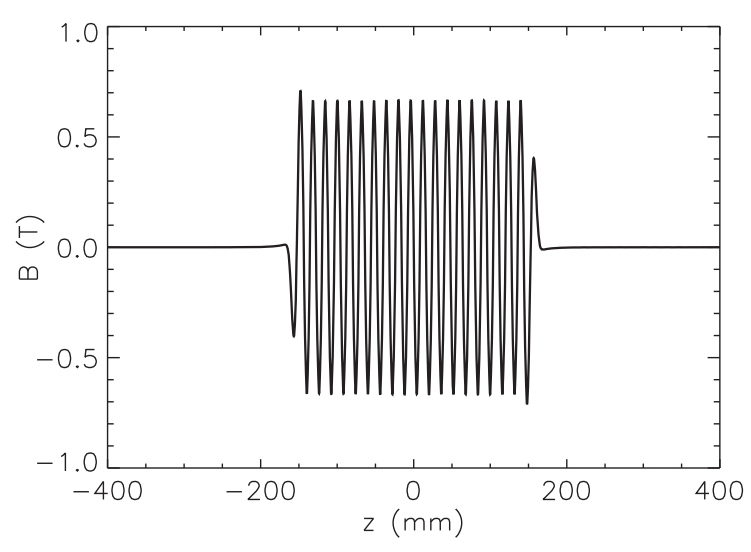

FIG. 10. SCU0 vertical magnetic field measured with moving Hall probe at the magnet current of $500 \mathrm{~A}$. 


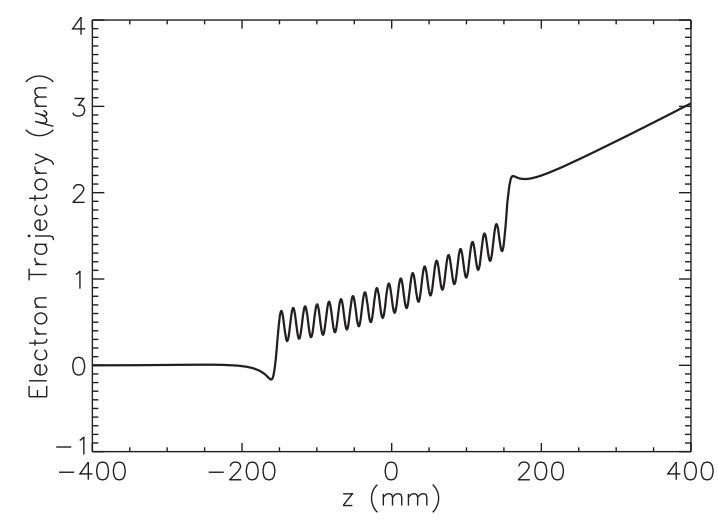

FIG. 11. Electron trajectory in the SCU0 for the APS electron beam of $7.0 \mathrm{GeV}$ derived from the measured magnetic field shown in Fig. 10.

5th harmonics. The ratios slightly increase with magnet current.

In SCU0, the field integrals are minimized using corrector coils. The corrector coil currents are varied based on the value of the main coil current, Fig. 12, as defined in a look-up table that was tuned during the cold test. In the end, very small changes were achieved for the field integrals when the main current was varied between $200 \mathrm{~A}$ and $600 \mathrm{~A}$-less than $60 \mu \mathrm{T} \mathrm{m}$ for the first field integral and less than $80 \mu \mathrm{T} \mathrm{m}^{2}$ for the second field integral. Dynamical changes in the field integrals of similar magnitude were observed during intentional magnet quenches. The requirements for maximum first- and second-field integral errors (vertical field) are $100 \mu \mathrm{T} \mathrm{m}$ and $100,000 \mu \mathrm{T} \mathrm{m}^{2}$, respectively, over the full undulator operating range, to keep the beam orbit perturbation to within $10 \%$ of the beam size [30].

The integrated field uniformity for both the vertical and horizontal field components was measured with a rotating coil over a horizontal range of $\pm 4 \mathrm{~mm}$. It was found that a skew quadrupole component of $12 \mathrm{mT}$ (at $500 \mathrm{~A}$ ) was present, which is larger than the APS undulator error tolerance of $5 \mathrm{mT}$ for a normal and skew integrated

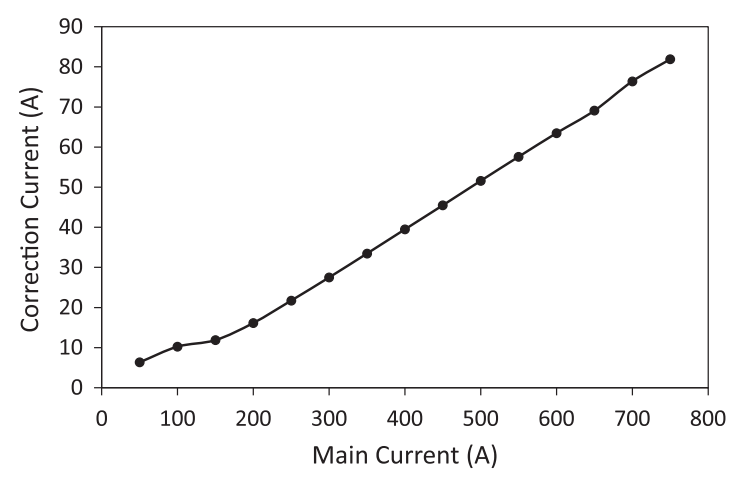

FIG. 12. Dependence of the corrector coil current on the main coil current for the SCU0.

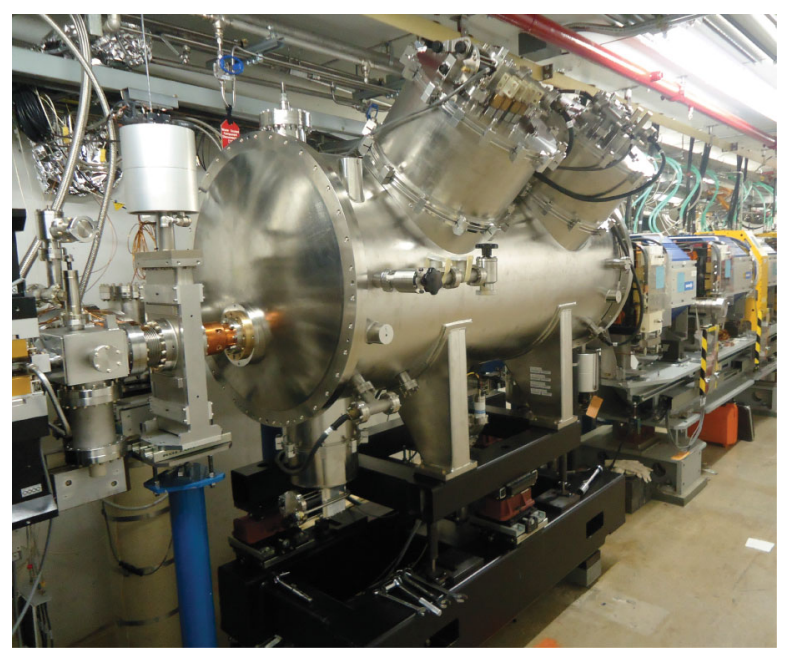

FIG. 13. Photograph of SCU0 installed into Sector 6 of the APS storage ring.

quadrupole [30]. This skew component of the field is believed to be due to net horizontal currents flowing on the back sides of the magnetic cores. These currents are caused by the chosen geometry of the coil winding with crossover wires between every other winding pack [16]. To suppress this undesirable effect, a new coil winding scheme will be implemented in the next device. Compensation of the skew quadrupole during machine operations is described below.

The successful completion of the SCU0 stand-alone cold test enabled installation of the device into Sector 6 of the APS storage ring in December 2012, Fig. 13.

\section{SCUO OPERATING EXPERIENCE}

\section{A. Commissioning}

In order to ensure continued reliable operation of the facility for APS users, stringent requirements must be met by all insertion devices that are installed in the APS storage ring. In the case of SCU0, all requirements were satisfied during a short but detailed beam commissioning in January 2013: (a) When powered, SCU0 is transparent to normal user operation; i.e., it does not measurably increase the storage ring impedance, or decrease the injection efficiency or electron beam lifetime; (b) When powered, SCU0 only perturbs the beam within the beam stability specifications, and (c) SCU0 is sufficiently protected from beam-induced heat loads; i.e., does not exceed the cryosystem cooling capacity (Table IV). To establish that these requirements were indeed met, a detailed commissioning plan was carried out in several steps, including assessment of thermal and vacuum monitoring, magnet alignment, cryogenic performance, beam orbit stability, quench response, endcoil field correction, x-ray performance, and operation procedures. Approximately 110 hours were used for SCU0 commissioning. The SCU0 was released for user operation on January 29, 2013. 


\section{B. Observed heat load}

The SCU0 beam-induced heat loads are calculated and presented in [19]. Using the measured load maps of cryocoolers, we estimated the observed heat loads on the thermal stages in the SCU0 as listed in Table VII. In this table, the 4-K stage refers to the SCU0 magnet and helium circuit, the $10-\mathrm{K}$ stage is the vacuum chamber and the internal thermal shield, while the $30-\mathrm{K}$ stage corresponds to the outer thermal shield, the warm-to-cold transition parts of the vacuum chamber, and the current leads.

The higher than expected heat load on the 4-K stage is due to excessive heat leaking from the $10-\mathrm{K}$ stage through the support structure. As a result, the SCU0 is operating at a slightly higher pressure in the helium system. This issue is currently being addressed in the design of the next device by using in the standoff a material with lower thermal conductivity.

The heat load on the vacuum chamber is also higher than calculated in [19] where only the cold central part was taken into account. This is likely because the measured $10-\mathrm{K}$ stage heat load includes the resistive-wall vacuum chamber heat leaking from the warmer vacuum chamber transitions cooled by the $30-\mathrm{K}$ stage [ $6 \mathrm{~W}$ ( 24 bunches) or $0.7 \mathrm{~W}$ (324 bunches), from Table III], while in the 10-K stage design calculations this heat leak was not considered. Further analysis of the cold central part, which involves converting the calculated resistive-wall and synchrotron radiation power to temperature using the chamber-mounted heater calibration, shows good agreement (within 60\%) with measured central chamber temperatures under varying beam conditions, and the measured chamber temperatures are typically lower than predicted [31]. This is further evidence that the heat leak from the ends contributes to the measured $10-\mathrm{K}$ stage heat load.

The 30-K stage observed heat load varies with both the beam current and the beam bunch pattern due to imagecurrent heating of the warm-to-cold transitions of the vacuum chamber. Synchrotron radiation is well masked and the contribution to the warm-to-cold transition heating is negligible during operations. The $30-\mathrm{K}$ stage heating also depends on the magnet current because of the higher heat

TABLE VII. SCU0 observed and calculated heat loads.

\begin{tabular}{lccccc}
\hline \hline Beam current (mA) & 0 & 100 & 100 & 100 & 100 \\
\hline $\begin{array}{l}\text { Number of bunches } \\
\text { SCU0 current (A) }\end{array}$ & 0 & 24 & 324 & 24 & 24 \\
Observed (calculated) & & 0 & 0 & 500 & 690 \\
heat load (W) & 1.20 & 1.20 & 1.16 & 1.30 & 1.45 \\
4-K stage & $(0.5)$ & & & & \\
& 0.1 & 14.6 & 4.1 & 14.5 & 15.3 \\
10-K stage & & $(7.5)$ & $(3.4)$ & & \\
30-K stage & 80 & 97 & 85 & 112 & 128 \\
& $(75)$ & & & & \\
\hline \hline
\end{tabular}

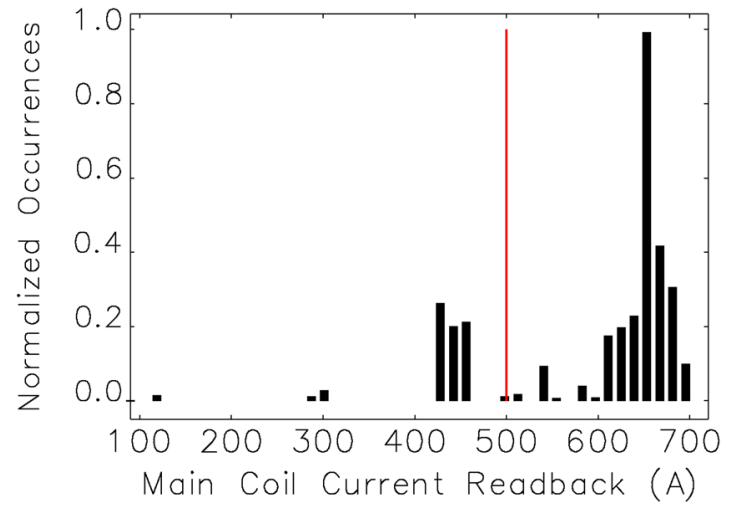

FIG. 14. Histogram showing the SCU0 magnet operational current normalized to the most frequent occurrence (design current is marked).

leak (at higher magnet current) through the current leads that are also cooled by this stage.

\section{Observed SCU0 behavior}

\section{Magnet}

The SCU0 magnet was designed to operate at the current of 500 A, but has been operated mainly at 600 $700 \mathrm{~A}$, reaching up to $0.8 \mathrm{~T}$ with no significant issues (see Fig. 14). By user demand SCU0 was operated for over 7800 hours, which is $88 \%$ of available user beam time (see Table VIII). SCU0 downtime caused by high $\mathrm{LHe}$ pressure was $<1 \%$. For the remaining $11 \%$ of available beam time, SCU0 was not operated by user choice. SCU0 was tested at $150 \mathrm{~mA}$ beam current (324 bunches), 50\% higher than it was designed for, with no significant issues.

\section{Cooling system}

In the SCU0 the cooling power is provided by four cryocoolers. We observed, in Table IX, that actual temperatures in the system are at or below the design levels given in Table IV. One can therefore conclude that a cooling system based on cryocoolers can provide adequate cooling for a superconducting undulator.

As mentioned above, the SCU0 superconducting magnet is cooled by liquid helium that passes through the channels in the magnet cores. Liquid helium (LHe) is contained in an internal tank that was initially filled with about 50 liters of

TABLE VIII. SCU0 Operational Statistics.

\begin{tabular}{lcccc}
\hline \hline & $\begin{array}{c}\text { APS } \\
\text { delivered } \\
(\mathrm{h})\end{array}$ & $\begin{array}{c}\text { SCU0 } \\
\text { operating } \\
(\mathrm{h})\end{array}$ & $\begin{array}{c}\text { SCU0 } \\
\text { down } \\
(\mathrm{h})\end{array}$ \\
\hline 2013 & Jan-Dec & 4872 & 4169 & 20 \\
2014 & Jan-Oct & 4075 & 3703 & 42 \\
Total & & 8947 & 7872 & 62 \\
\hline \hline
\end{tabular}


TABLE IX. SCU0 design and observed temperatures.

\begin{tabular}{lcc}
\hline \hline Parameter & $\begin{array}{c}\text { Design } \\
\text { temperature } \\
(\mathrm{K})\end{array}$ & $\begin{array}{c}\text { Observed } \\
\text { temperature } \\
(\mathrm{K})\end{array}$ \\
\hline Superconducting magnet & 4.2 & 4.3 \\
Vacuum chamber & 20 & $9-13$ \\
Internal thermal shield & 20 & $11-13$ \\
Outer thermal shield & 60 & $34-36$ \\
\hline \hline
\end{tabular}

LHe. Together with the magnet and associated piping, the LHe tank comprises a closed system. No helium loss in the system was observed in the first 12-month period during normal operation, as shown in Fig. 15.

There was one occasion in December 2013 when the cryocooler compressors stopped for a period of several hours when the chilled water supplied by an external water plant was shut down for maintenance. As a result, the system started to warm up, and some helium was vented. This is labeled " 1 " in the figure. The second drop in the LHe level visible on the plot, labeled " 2 ", is due to a small loss of helium during the replacement of a pressure safety valve. A third small drop occurred during a chilled water plant outage, labeled " 3 ". We did not add any helium to the system after three losses. This did not cause any deterioration in the cooling system behavior.

\section{SCUO magnet position stability}

The vertical position of the SCU0 vacuum chamber, which is a part of the cold mass, was measured with the electron beam in January 2013 after the initial cool down and chamber realignment, using a novel method developed at APS [32]. The electron beam was steered vertically within the chamber while observing the response of thermal sensors mounted on the chamber. The thermal sensor minima determine the vertical center of the SCU0 chamber

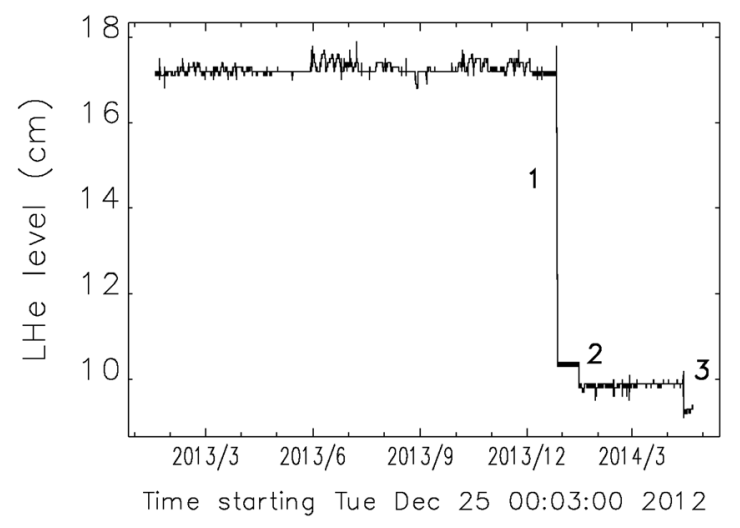

FIG. 15. Level of liquid helium in an internal tank over a 15-month period. Labels 1, 2, 3 are discussed in the text. with respect to the user orbit. Similar measurements were repeated several times, indicating that the vacuum chamber shifted down by up to $100 \mu \mathrm{m}$ relative to the initial measurement and has remained stable thereafter, shown in Fig. 16. This insignificant movement can be attributed to creep of the Kevlar strings that are holding the cold mass and the vacuum chamber inside the SCU0 cryostat. The overall vertical chamber alignment at the SCU0 magnet cores (center three sensors) is about $0.35 \mathrm{~mm}$ below the user beam orbit. The unique challenges of SCU chamber alignment, given the extreme temperature changes in combination with limited access to the magnet structure and vacuum chamber are discussed in [33]. There were no observed negative effects of this misalignment either with respect to the undulator performance or protection from excessive beam-induced heating. Nevertheless, the entire cryomodule was vertically realigned to within $0.05 \mathrm{~mm}$ of the user orbit during the second year of operation. Significant knowledge was gained from the SCU0 chamber alignment and installation and many improvements are being implemented in the assembly and alignment of the next device.

\section{Quenches}

The SCU0 superconducting magnet was found to quench frequently during beam dumps triggered by the Machine Protection System (MPS) (SCU0 is powered off during intentional beam dumps.) A quench causes a magnet temperature rise from $4.3 \mathrm{~K}$ up to $10-15 \mathrm{~K}$. It takes only 1-3 min for the core temperature to return back to $4.3 \mathrm{~K}$ (see left panel in Fig. 17).

The pressure in the LHe tank after a quench is shown in the right panel in Fig. 17. It is observed that the pressure rise in the tank due to a quench is about 70 Torr. It is also noticeable that the pressure rise drops in about $10 \mathrm{~min}$ to half the level of the pressure spike, but it then takes up to several hours for the pressure to return back to the initial level. Typically in operations, the pressure after a quench

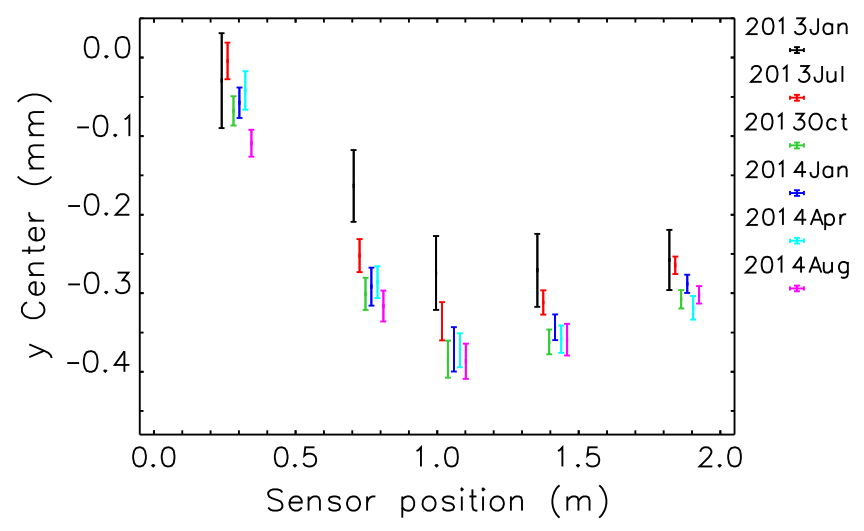

FIG. 16. Measured vertical position of the vacuum chamber over 15-month period using beam-based method. 

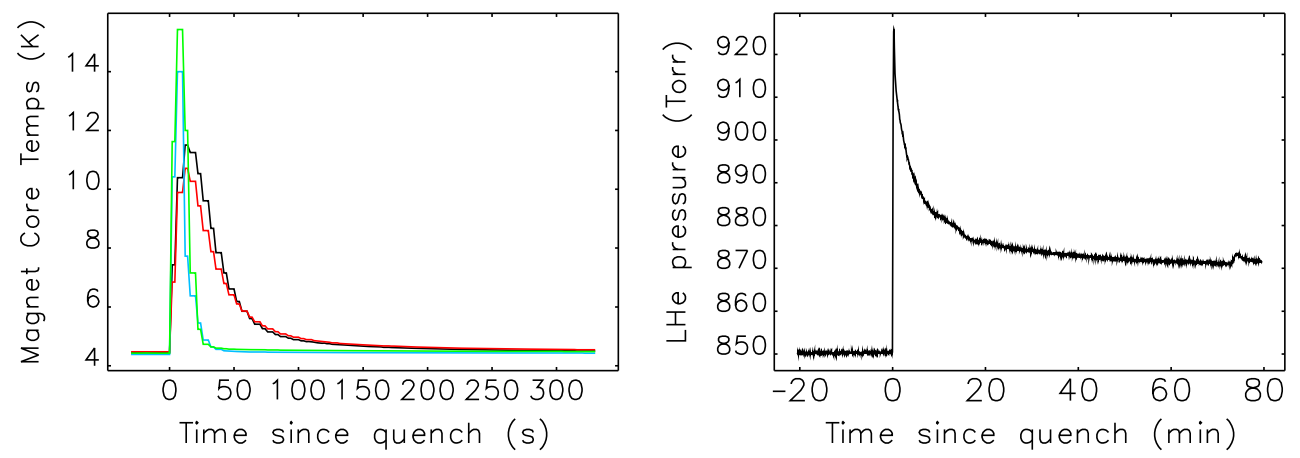

FIG. 17. Left panel: Magnet core temperatures after a quench measured by four temperature sensors on two magnet cores, shown in different colors. Right panel: Pressure variation in the liquid helium system shown for the same quench.

does not reach the threshold of 1000 Torr for opening the pressure safety valve of the LHe circuit. Once the pressure decreases below 900 Torr, the SCU0 magnet can be powered again.

It should be noted that the LHe system exhibits a complicated behavior despite its apparent simplicity. We are planning to study the LHe circuit response to a quench more rigorously and to publish the results separately.

Simulations suggest that a beam loss of $>50 \mathrm{pC}$ deposits energy sufficient to raise the coil temperature above the critical temperature. This is a small fraction of the $375-\mathrm{nC}(100 \mathrm{~mA})$ circulating beam. To better control the beam loss location at the level required, a dedicated abort kicker system is being designed. An abort kicker test that involved triggering the injection kickers with the MPS demonstrated that beam losses at SCU0 were significantly reduced and that a quench was prevented. Using the injection kickers as an abort system is not compatible with top-up operation.

\section{SCU0 effect on the electron beam}

\section{SCUO transparency}

Prior to installing SCU0, a room temperature test chamber with virtually the same length, aperture, and transitions was installed in the same location in the storage ring. This test was done to confirm that an unpowered SCU0 does not affect normal beam operation; i.e., test whether it increases the storage ring impedance and/or local vacuum pressure, decreases the beam injection efficiency or beam lifetime, or else lowers the beam collective instability threshold. We confirmed that the test chamber did not adversely affect normal user operation. As expected, the SCU0 chamber also preserved normal user operation: the operational single bunch limit of $16 \mathrm{~mA}$ was preserved, and $100 \mathrm{~mA}$ could be stored in all bunch timing patterns at APS [34]. The measured betatron tune shift with current, which is a measure of the transverse impedance, did not change within the experimental error. The beam injection efficiency and beam lifetime were both in the normal range after the standard startup procedures were carried out. The beam injection efficiency and beam lifetime are also unaffected when SCU0 is powered, which is relevant for top-up operation.

\section{Machine vacuum}

There were no beam chamber vacuum pressure issues and no negative effect observed on the beam. The vacuum chamber was cleaned using the standard UHV techniques-prewash and wash (ultrasound) with $2 \%$ solution of Citranox at $65^{\circ} \mathrm{C}$, cold rinse with deionized water, dry with $38^{\circ} \mathrm{C}$ nitrogen-but was necessarily exposed to air during magnetic measurements. After the components were installed in the storage ring the system was roughed down to about 200 nTorr on the cold cathode gauge (CCG) located in the downstream transition. A 24hour, $130-{ }^{\circ} \mathrm{C}$ bakeout was then performed on the transitions upstream and downstream of SCU0. Bakeout of the SCU0 vacuum chamber was not required, as shown below. The CCG pressure after the bakeout and before the SCU0 was cooled down was at 3 nTorr. After cool-down and prior to injecting beam, the vacuum pressure was measured as 0.4 nTorr. The first 100-mA beam caused pressure transients in the 10-nTorr range, but after about 4 days of operation $(10 \mathrm{~A} \mathrm{~h})$, the pressure settled at 3 nTorr. After $200 \mathrm{~A}-\mathrm{h}$, the pressure was about $0.8 \mathrm{nTorr}$.

\section{Cryocooler-induced vibrations}

Mechanical vibration of the warm vacuum chamber just upstream of the SCU0 caused by the SCU0 cryocoolers was measured in the spectral range of $2-100 \mathrm{~Hz}$. The integrated vibrational power spectral density increased from $0.38 \mu \mathrm{m} \mathrm{rms} \mathrm{with} \mathrm{the} \mathrm{cryocoolers} \mathrm{off} \mathrm{to} 0.65 \mu \mathrm{m}$ rms with the cryocoolers on. Cryocooler vibration has not been observed to adversely affect beam stability.

\section{Magnetic performance}

The SCU0 field-error tolerances are the same as for the other planar insertion devices (IDs) installed in APS [30]. 


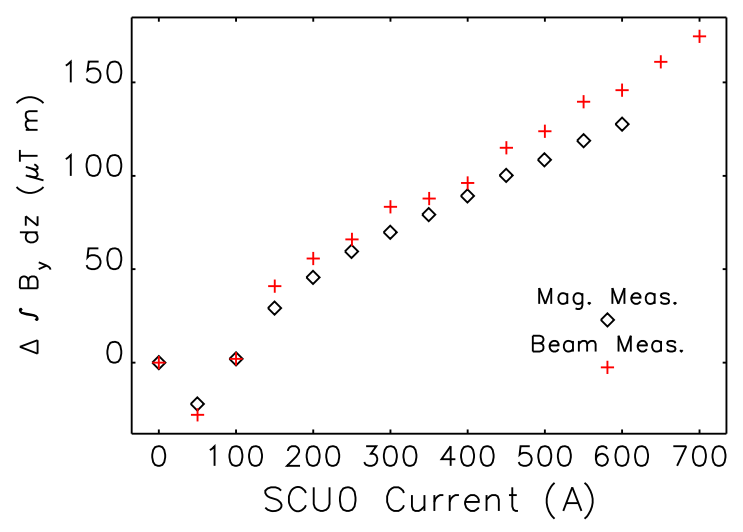

FIG. 18. Field integral measurement with beam.

The field-integral error tolerances were specified using simulations that include slow orbit correction and fast orbit feedback. The magnet measurements show that the SCU0 magnet performs better for all design parameters except the skew quadrupole component mentioned earlier. At the maximum coil current, the skew quadrupole error produced a $10 \%$ change in the typical $1.5 \%$ beam emittance ratio. This effect is easily corrected by implementing feedforward using the adjacent skew quadrupoles, which is checked at the beginning of every run and adjusted as necessary. The first field integral was measured with the beam by measuring the orbit correction response while scanning the SCU0 current. The beam measurements agreed well with the magnet measurements, as shown in Fig. 18, where the vertical axis is the change in the first field integral and $100 \mu \mathrm{Tm}$ is equal to $4.2 \mu \mathrm{rad}$.

\section{Effect of quenches}

Quenches may produce a field disturbance on a time scale that is too fast for the real-time orbit feedback [35] to correct. If the perturbation is very large, the resulting beam trajectory displacement at the undulators could exceed the beam position limit detector (BPLD) limits and cause a beam dump. The maximum orbit perturbation is proportional to the quantity $\mathcal{A}=\sqrt{I_{1}^{2}+\left(I_{2} / \beta_{\mathrm{U}}\right)^{2}}$, where $I_{1}$ and

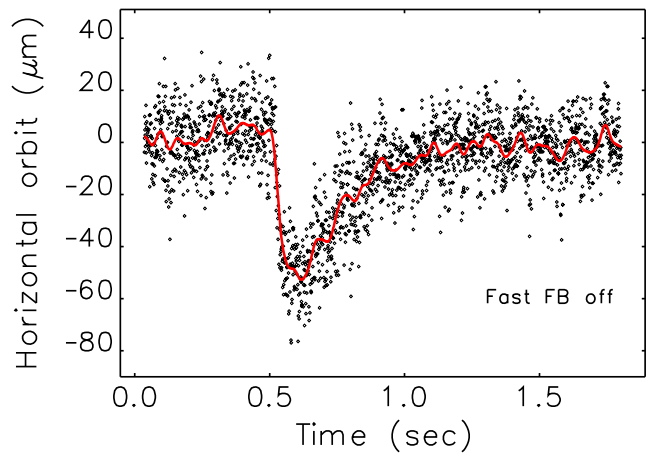

$I_{2}$ are the first- and second-field integrals, respectively and $\beta_{\mathrm{U}}$ is the beta function at the undulator ends. To avoid dumping the beam during a quench, the specification for $\mathcal{A}$ is $2100 \mu \mathrm{Tm}$ and $350 \mu \mathrm{Tm}$ for the $\mathrm{x}$ and $\mathrm{y}$ fields, respectively. Magnet measurements show that SCU0 meets this specification during a heater-induced quench. Tests with the beam, shown in Fig. 19, demonstrate that an induced quench at $0.5 \mathrm{sec}$ produced only small beam motion, even without fast orbit feedback running, and did not cause loss of the beam. Fast orbit feedback reduces the orbit perturbation by a factor of five. As seen in Fig. 19, slow orbit recovery occurs over about $0.5 \mathrm{sec}$.

Besides the many MPS-dump-induced quenches, during normal APS stored-beam operations SCU0 quenched only four times over a 21-month period. These quenches did not cause any beam loss, and quench recovery did not affect storage ring operations. The impact of all quenches on SCU0 operation, including those that occur frequently with MPS-triggered beam dumps, has been minimal due to rapid SCU0 recovery, typically less than $30 \mathrm{~min}$.

\section{E. Photon flux measurements}

The x-rays produced by SCU0 were characterized by measuring the photon flux passing through a bent-Laue monochromator and comparing the SCU0 photon flux with that from an in-line 3.3-cm-period length permanent magnet hybrid undulator U33. At $85 \mathrm{keV}$, the 0.33 -m-long SCU0 produced $\sim 45 \%$ higher photon flux through an aperture than the 2.3-m-long U33. Figure 20 shows the simulated photon flux calculated from the measured magnetic fields compared to the measured photon flux at $85 \mathrm{keV}$ for SCU0, and the measured photon flux for U33 (inset). In these measurements, the U33 gap was scanned from $11.0 \mathrm{~mm}$ to $12.0 \mathrm{~mm}$ to maximize the photon flux. Smaller than expected flux from SCU0 is likely due to an alignment error of the aperture $(0.5 \mathrm{~mm} \times 0.5 \mathrm{~mm})$, located $40 \mathrm{~m}$ from the undulator, with respect to the photon beam. Nevertheless, this measurement demonstrates the enhanced capability of superconducting undulators for generating higher photon fluxes at higher energies.

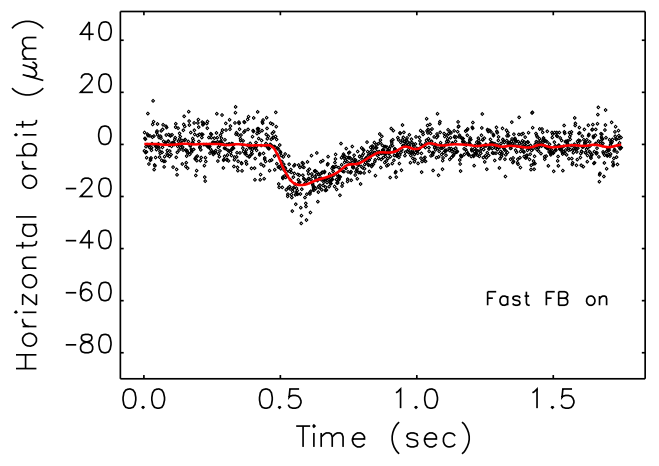

FIG. 19. Effect of induced quench on the beam orbit. Left panel: Slow orbit correction only. Right panel: Fast orbit feedback (FB) turned on. 


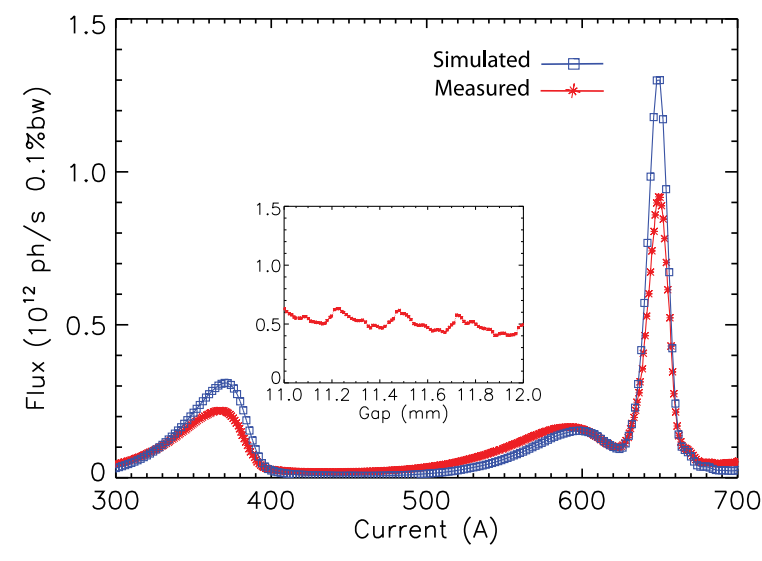

FIG. 20. Photon flux comparisons at $85 \mathrm{keV}$. Main: simulated and measured SCU0 photon flux as the main coil current is scanned. Inset: measured photon flux of in-line U33 as the gap is scanned. Inset vertical axis units are the same as the main plot.

\section{SUMMARY}

An almost decade-long activity focused on development of superconducting undulators for the APS reached a significant milestone in January of 2013 with the installation in the APS storage ring of a prototype undulator, SCU0. Since then, the device has been in user operation. The nearly two-year-long experience of operating this device allows us to conclude that: the beam heat load has been correctly estimated taking heat leaks into account, a cryocooler-based cooling system has proven to be efficient, helium loss-free operation is possible, and cryocooler-induced mechanical vibrations do not disturb the beam. SCU0 was successfully operated in all bunch timing patterns at the APS while protected from excessive beam-induced heating. At least for this short device, we showed that a SCU with sufficient field quality can be built without shimming. Finally, SCU quenches do not cause a beam dump, and the SCU beam chamber does not require baking.

\section{ACKNOWLEDGMENTS}

The authors acknowledge the long-term continuous support of the APS management. We also thank the APS staff for many valuable contributions. This work was supported by the U.S. Department of Energy, Office of Science, under Contract No. DE-ACO2-O6CH11357. Work by L. Boon and A. Vella was partially supported by the National Science Foundation under Grant No. PHY1307300 .

[1] K. Soutome, S. Date, H. Ego, T. Fukui, M. Hara, N. Hosoda, Y. Kawashima, M. Kodera, N. Kumagai, T. Magome et al., Generation of high-energy synchrotron radiation with a 10-T superconducting wiggler installed in the SPring-8 storage ring, in Proceedings of the 2003 Particle Accelerator Conference, Portland, OR (IEEE, Piscataway, NJ, 2003), p. 250.

[2] A. Temnykh, J. Crittenden, D. Rice, and D. Rubin, Beam based characterization of a new 7-pole superconducting wiggler at CESR, in Proceedings of the 2003 Particle Accelerator Conference, Portland, OR (IEEE, Piscataway, NJ, 2003), p. 3425.

[3] L. Tosi, C. Knapic, and D. Zangrando, The ELETTRA superconducting wiggler, in Proceedings of the 9th European Particle Accelerator Conference, Lucerne, 2004 (EPS-AG, Lucerne, 2004), p. 390 [http://accelconf .web.cern.ch/AccelConf/e04/PAPERS/MOPKF039.PDF].

[4] D. Robin, J. Krupnick, R. Schlueter, C. Steier, S. Marks, B. Wang, J. Zbasnik, R. Benjegerdes, A. Biocca, P. Bish et al., Superbend upgrade on the Advanced Light Source, Nucl. Instrum. Methods Phys. Res., Sect. A 538, 65 (2005).

[5] C. H. Chang, C. S. Hwang, H. H. Chen, H. P. Chang, F. Y. Lin, M. H. Huang, T. C. Fan, J. C. Jan, C. C. Chang, G. Y. Hsiung, and J. R. Chen, In-achromatic superconducting wiggler in Taiwan Light Source: installation and test results, Proceedings of the 10th European Particle Accelerator Conference, Edinburgh, Scotland, 2006 (EPS-AG, Edinburgh, Scotland, 2006), p. 3613.

[6] S. V. Khruschev, E. A. Kuper, V. H. Lev, N. A. Mezentsev, E. G. Miginsky, V. V. Repkov, V. A. Shkaruba, V. M. Syrovatin, and V. M. Tsukanov, Superconducting 63-pole 2-T wiggler for Canadian Light Source, Nucl. Instrum. Methods Phys. Res., Sect. A 575, 38 (2007).

[7] J. C. Schouten and E. C. M. Rial, Electron beam heating and operation of the cryogenic undulator and superconducting wiggler at Diamond, in Proceedings of the 2nd International Particle Accelerator Conference, San Sebastián, Spain (EPS-AG, Spain, 2011), p. 3323.

[8] S. Casalbuoni, M. Hagelstein, B. Kostka, R. Rossmanith, M. Weisser, E. Steffens, A. Bernhard, D. Wollmann, and T. Baumbach, Generation of x-ray radiation in a storage ring by a superconductive cold-bore in-vacuum undulator, Phys. Rev. ST Accel. Beams 9, 010702 (2006).

[9] S. H. Kim, C. Doose, R. L. Kustom, E. R. Moog, and I. Vasserman, R\&D on short-period NbTi and $\mathrm{Nb}_{3} \mathrm{Sn}$ superconducting undulators for the APS, in Proceedings of the 21 st Particle Accelerator Conference, Knoxville, TN, 2005 (IEEE, Piscataway, NJ, 2005), p. 2419.

[10] E. Trakhtenberg, Y. Ivanyushenkov, C. Doose, and M. Kasa, Design of the magnet structure for the APS superconducting undulator, in Proceedings of MEDSI 2010 (Diamond Light Source Ltd, Didcot, 2010).

[11] J. Fuerst, C. Doose, Q. Hasse, Y. Ivanyushenkov, M. Kasa, E. Moog, J. Pfotenhauer, D. Potratz, D. Skiadopoulos, V. Syrovatin, and E. Trakhtenberg, Cryostat design and development for a superconducting undulator for the APS, AIP Conf. Proc. 1434, 901 (2012).

[12] D. Potratz, J. Pfotenhauer, Q. Hasse, Y. Ivanyushenkov, E. Moog, and R. Kustom, A helium thermosiphon cooling loop for the APS superconducting undulator, AIP Conf. Proc. 1434, 1991 (2012).

[13] M. Fritz, T. Hezel, M. Homscheidt, H. O. Moser, R. Rossmanith, Th. Schneider, H. Backe, S. Dambach, F. Hagenbuck, K.-H. Kaiser, W. Lauth, A. Steinhof, and 
Th. Walcher, First experiments with a 100 period superconductive undulator with a period length of $3.8 \mathrm{~mm}$, in Proceedings of the 6th European Particle Accelerator Conference, Stockholm, 1998(IOP, London, 1998), p. 2234.

[14] Supercon Inc, 830 Boston Turnpike Road, Shrewsbury, MA 01545, U.S.A.

[15] James A. Clarke, The Science and Technology of Undulators and Wigglers (Oxford University Press, New York, 2004), p. 118.

[16] S. H. Kim, C. Doose, R. L. Kustom, E. R. Moog, and K. M. Thompson, Design and development of a short-period superconducting undulator at the APS, IEEE Trans. Appl. Supercond. 15, 1240 (2005).

[17] N. A. Mezentsev, Superconducting magnets for SR generation in Budker INP, in Proc. of Russian Particle Accelerator Conf. 2006 (RUPAC) (JINR, Dubna, 2006).

[18] B. Baudouy, Heat and mass transfer in two-phase He I thermosiphon flow, AIP Conf. Proc. 613, 1514 (2002).

[19] K. C. Harkay, L. Boon, M. Borland, Y.-C. Chae, R. Dejus, J. Dooling, C. Doose, L. Emery, Y. Ivanyushenkov, M. Jaski, M. Kasa, S. H. Kim, R. L. Kustom, V. Sajaev, Y. Shiroyanagi, and X. Sun, Beam-induced heat load predictions and measurements in the APS superconducting undulator, in Proceedings of North American Particle Accelerator Conference 2013 (JACoW, Geneva, 2013), p. 1055.

[20] L. Boon, R. Dejus, K. C. Harkay, and M. Jaski, Comparison of simulations and analytical theory of radiation heating on the Advanced Photon Source superconducting undulator, in Proceedings of North American Particle Accelerator Conference 2013 (JACoW, Geneva, 2013), p. 1148.

[21] K. C. Harkay, L. Boon, A. Garfinkel, Y. Ivanyushenkov, R. L. Kustom, E. Moog, and E. Trakhtenberg, Electron cloud issues for the APS superconducting undulator, in Proceedings of the 24th Particle Accelerator Conference, PAC-2011, New York, 2011 (IEEE, New York, 2011), p. 1283.

[22] R. Powell, W. Hall, and H. Roder, Low temperature transport properties of commercial metals and alloys. II. Aluminums, J. Appl. Phys. 31, 496 (1960).

[23] C. Y. Ho and T. K. Chu, Electrical resistivity and thermal conductivity of nine selected AISI stainless steels, Purdue University Technical Report No. DTIC A129160; CINDAS Report No. 45, 1977.

[24] Y.-C. Chae, Impedance database II for the Advanced Photon Source storage ring, in Proceedings of the 22nd
Particle Accelerator Conference, PAC-2007, Albuquerque, NM (IEEE, New York, 2007), p. 4336.

[25] K. Bane and S. Krinsky, Impedance of a small gap undulator vacuum chamber, in Proceedings of the 15th Particle Accelerator Conference, PAC-1993, Washington, DC, 1993 (IEEE, New York, 1993), p. 3375.

[26] A. B. Pippard, The surface impedance of superconductors and normal metals at high frequencies. II. The anomalous skin effect in normal metals, Proc. R. Soc. A 191, 385 (1947).

[27] Y. Ivanyushenkov, M. Abliz, C. Doose, M. Kasa, E. Trakhtenberg, I. Vasserman, N. Mezentsev, V. Tsukanov, and V. Lev, Development status of a magnetic measurement system for the APS superconducting undulator, in Proceedings of the 24th Particle Accelerator Conference, PAC-2011, New York, 2011 (IEEE, New York, 2011), p. 1286.

[28] C. Doose and M. Kasa, Magnetic measurements of the first superconducting undulator at the Advanced Photon Source, in Proc. of North American Particle Accelerator Conf. 2013 (JACoW, Geneva, 2013), p. 1235.

[29] James A. Clarke, The Science and Technology of Undulators and Wigglers (Oxford University Press, New York, 2004), p. 172.

[30] Y.-C. Chae and G. Decker, Advanced Photon Source insertion device field quality and multipole error specification, in Proceedings of the Particle Accelerator Conference, Dallas, TX, 1995 (IEEE, New York, 1995), p. 3409 .

[31] L. E. Boon, Beam-induced radiation heating on the superconducting undulator at the Advanced Photon Source, Ph.D. thesis, Purdue University, 2014.

[32] K. C. Harkay, L. Boon, M. Borland, L. Emery, R. L. Kustom, V. Sajaev, Y. Shiroyanagi, and A. Xiao, Beam-based alignment of the first superconducting undulator at the APS, in Proc. of North American Particle Accelerator Conf. 2013 (JACoW, Geneva, 2013), p. 1058.

[33] J. M. Penicka, C. Doose, K. Harkay, Q. Hasse, W. Jansma, Y. Ivanyushenkov, M. Kasa, D. Skiadopoulos, E. M. Trakhtenberg, and S. Wesling, Alignment of superconducting undulators at the APS, in Proceedings of 2014 International Workshop on Accelerator Alignment (IWAA2014), Beijing, China (IHEP, Beijing, 2014).

[34] http://www.aps.anl.gov/Facility/Status.

[35] J. Carwardine and F. Lenkszus, Real-time orbit feedback at the APS, AIP Conf. Proc. 451, 125 (1998). 